\title{
О.Г. Твердохлеб
}

\section{ОБЩАЯ ГРАММАТИЧЕСКАЯ ХАРАКТЕРИСТИКА КОНСТРУКЦИЙ С СОВОКУПНЫМ СУБЪЕКТОМ ПРИ ГЛАГОЛАХ СОЕДИНЕНИЯ}

\begin{abstract}
Статья подводит некоторые итоги изучения грамматических особенностей конструкций с двумя (и более) именами в субъектной позищии подлежащего при глаголах «соединить/соединять» в активной форме. В работе акиентируется внимание на морфологических особенностях глагола «соединения» в указанных конструкииях. Особое внимание уделено средствам связи между двумя (и более) именами в позиции подлежащего при глаголе "соединения», а также возможности / невозможности перестановки этих элементов. Материал данной статьи будет интересен специалистам в области исследования взаимных конструкций (проблемы реципрока) и симметричньхх отношений.

Ключевые слова: подлежащеее, лексико-семантическая группа глаголов, совокупный субъект, союзная связь.
\end{abstract}

Русская лингвистика последней трети прошлого века и начала века нынешнего активно исследует семантический синтаксис, однако до сих пор остается еще много нерешенных проблем, среди которых однозначное определение «субъекта». Традиционно его отождествляли с синтаксическим понятием «подлежащее». Исследование субъектной семантики связано было с описанием падежных значений (М.В. Ломоносов, Ф.И. Буслаев, А.А. Шахматов, А.М. Пешковский, В.В. Виноградов). Во второй половине XX в. исследование субъекта в лингвистике начинают связывать с синтаксической семантикой (С.Д. Кацнельсон, Н.Д. Арутюнова, Г.А. Золотова, Ю.Д. Апресян, А. Вежбицка, А.В. Бондарко, Е.В. Падучева, З.Д. Попова и др.), исследуются значения субъекта, обусловленные, в частности, схемой предложения (Н.Ю. Шведова, В.И. Казарина).

Непротиворечивое оперирование понятием субъекта важно в исследованиях петербургской типологической школы (А.А. Холодович, В.С. Храковский, В.Н. Недялков и др.), особенно при анализе глагольных лексем, так как названная глаголом ситуация (как структурно-семантический центр предложения) предполагает определенный качественный и количественный состав участников, необходимых для ее реализации и определяемых по «лексикографическому толкованию слова, выражающего данную ситуацию» [1. C. 6].

Предлагаемая статья связана с исследованием конструкций, образованных глаголами лексико-семантической группы соединения [2. С. 38; 3. С. 8791], или глаголами контакта (контактивы) [4], предполагающими наличие субъектной валентности. Из различных источников, в том числе из Национального корпуса русского языка [5], нами выявлено более трех тысяч при- 
меров с многозначным глаголом «соединить / соединять» в разных реализациях (словарь [6. С. 442-443] фиксирует 11 лексических значений), субъектная валентность которых может заполняться по-разному: изосемически и неизосемически [7. С. 163]. Ранее нами на большом иллюстративном материале было показано, что в субъектной позиции при глаголах соединения традиционно выделяемому Агенсу соответствуют разные таксономические классы имен (лица, сверхъестественные существа, животные) [8-9]. Цель данной работы - выявить и описать грамматические (морфологических и синтаксических) особенности конструкций, включающих в свой состав два (и более) элемента в субъектной позиции подлежащего при глаголах «соединить / соединять» в активной форме.

Методика описания конструкций с совокупным субъектом нужна для исследования взаимных конструкций (проблема реципрока) [10] и симметричных отношений [11. С. 280-281].

Учитывая сложность анализа всех семантических акантов, которые могут занимать субъектную валентность (мы планируем сделать это в следующей статье), мы ограничимся: а) описанием морфологических особенностей глагола, функционирующих в указанных конструкциях; б) определением количественного состава элементов в субъектной позиции, выявлением и описанием средств связи между этими элементами, а также возможности / невозможности перестановки этих элементов.

В нашей картотеке при активной форме анализируемых глаголов в позиции подлежащего могут быть представлены:

а) два и более имени существительных в форме именительного паде-

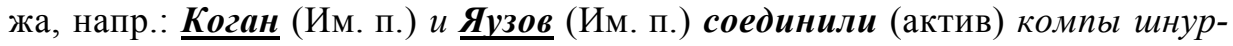
ком [12];

б) два местоимения (в единичных примерах) в форме именительного падежа: Янус имеет с Ямой то общее, что они «парны», «двулики» и что $u \underline{\text { mom }}$ (мест., Им. п.) и другой (мест., Им. п.) соединяют (актив) две сферы мира - либо «прошлое» и «будущчее», либо «то, что сзади» и «то, что спереди», либо «иарство живых» и «иарство мертвых» [13. С. 91].

Исследованный нами материал свидетельствует, что два (или более) имени репрезентированы в позиции субъекта при разных формах глагола, в частности:

- при форме глагола несовершенного вида «соединять» и совершенного вида «соединить», ср.: ...хотя бы Австрия и Франция соединили (сов. в.) свои силь [14. Т. 8. С. 275]; Почти литенное очертаний в свете звезд лицо и голос, тепльй, близкий, как бы соединяли (несов. в.) нас [15. Т. 1];

- $\quad$ при формах глагола изъявительного наклонения всех трех времен:


глаз Соединяют (изъяв. накл.; наст. вр.) нас навеки [16];

○ будущего: ...когда судьба и их собственные усилия соединят (изъяв. накл.; буд. вр.) их в одном городе и под одной крышей [17. Т. 7. С. 389];

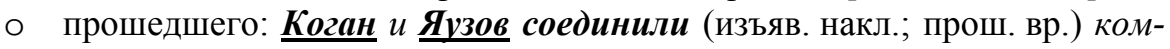
пье шнурком [12];

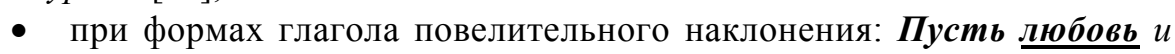
взаимопонимание... соединит (повел. накл.) наши судьбы при этой жиз- 
ни и в жизни будущеей [18] и сослагательного наклонения: ...общее глубокое горе и задушевная беседа... как бы ещче теснее соединили (сосл. накл.) Hac [19].

В описываемых случаях имена в позиции субъекта при глаголе соединить / соединять представлены:

- попарно (чаще): Когда Кассию был открыт путь, то Мариелл и $\underline{\text { Ме- }}$ пид соединили свои лагери [20];

- $\quad$ по три и более лексемы (реже): Алчность, злоба и длупость соединят людей в клубок, словно змей [21. С. 239].

Описываемые ряды имен в позиции субъекта соединяются между собой союзной связью (гораздо чаще) и бессоюзной (реже).

Два (или более) члена, представленных в позиции субъекта, обычно соединяет одиночный сочинительный соединительный союз $u$, который указывает на исчерпанность перечисляемого ряда, ср. примеры с двумя членами: ...самеи и самка соединили свои голоса в один непрерывный,

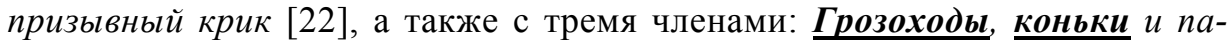
русные сани соединяли села [23. С. 234]. В случаях с повторяющимся союзом $u$ исчерпанности ряда нет: И xaлam, $u$ шапка соединяют в себе черты мужского и женского костюма [24. С. 91]. Ср возможное продолжение: и халат, и шапка, и обувь, и пояс соединяют в себе что-то.

Пара имен, соединенных одиночным союзом $u$, допускает перестановку членов, ср. возможные трансформации: ...нам важно знать, какие цувства $и$ стремленья соединяли членов дружеского союза [25. С. 107] $\rightarrow$ стремления и чувства соединяли. В позиции субъекта может быть представлено четыре однородных члена, соединенных союзом $u$ попарно. Тогда перестановка допустима внутри каждой пары имен, ср. возможное: ...mам смерть и слава

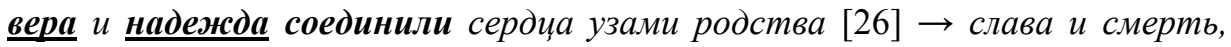
надежда и вера соединили.

Перестановка невозможна в тех случаях, когда последующий член содержательно обусловлен предыдущим. Например, в предложении с тремя членами субъектной сферы: Биротmо, жена его (притяж. мест.) и дочь соединили свои усилия [27. Т. 29] имя существительное жена содержательно связано (через указание с помощью притяжательного местоимения его) с предыдущим в ряду именем Биротто, что не допускает трансформации типа: *жена его и Биротто. Ср. другую, лишь внешне аналогичную конструкцию: ...когда ууба и их (притяж. мест.) собственные $\underline{\boldsymbol{y c u}}$ лия соединят их в одном городе и под одной крышей... [17. С. 389], где второй член усилия определяется также притяжательным местоимением ux. Однако здесь перестановка возможна, напр.: $\rightarrow$ их собственные усилия $u$ судьба соединят, так как местоимение $u x$ не обусловлено предыдущим именем судьба, представленным первым членом (нельзя: *ux cyдьба $u$ собственные усилия).

Перестановка членов, соединенных повторяющимся союзом $u$, также невозможна, если они репрезентированы двумя местоимениями, обусловленными один другим: Янус имеет с Ямой то общее, что они «парныл», «двулики» и что и тот (мест.) и другой (мест.) соединяют две сферы мира - либо 
«прошлое» и «будущеее», либо «то, что сзади» и «то, что спереди», либо «царство живых» и «иарство мертвых» [13. С. 91].

Именная пара с союзом не ... $а$ ( $а$ не) указывает на взаимное исключение, ср.: Их (Краггса и Кембла. - О.Т.) соединяет друг с другом не оценка автоpa, а общий прием [28]. Резкость взаимного исключения смягчена в союзе не... но (ноне), ср.: ...нине не выбор, но нужды соединяют людей... [29]. Перестановка членов, соединенных союзами не ... а (а не) и не ... но (но не), недопустима, так как при трансформации полностью меняется смысл высказывания, ср.: *не прием, а оценка соединяет.

Несколько явлений, из коорых возможно только одно, названо именной парой с разделительными союзами или, ли, ср.: Обрезательный ножс виноградаря или плуг таинственным образом соединяет человека с землей... [30]. Конструкции, включающие два члена в позиции субъекта, соединенные разделительным союзом, перестановку этих членов допускают, ср.: $\rightarrow$ плуг или нож соединяет. Однако невозможна перестановка членов в позиции субъекта в высказывании, если вводится относительное ограничение, в частности по отношению ко второму члену, при помощи вводных слов лучше сказать: Heобыкновенный случай, или, лучше сказать, судьба, соединила меня с Силою Миничем [31]. Ср. невозможные трансформации: *лучше сказать, судьба или случай и *судьба или, лучше сказать, случай.

Также невозможна перестановка членов в позиции субъекта, соединенных повторяющимся союзом ли, если они репрезентированы парой «имя существительное + местоимение, обусловленное этим же существительным»: Мыл с вами не подходящие друг к другу люди, но случай (сущ.) ли, другое ли цто (мест.) соединили нас, к сожалению, навсегда [32].

В паре имен, соединенных в позиции субъекта союзами не только... но $u$, не столько... но $u$, в семантическом плане формально равноправны два члена, но один из них актуализируется в направлении нарастания, напр.: ...соединяли этих великих писателей не только идеи великие, но и лю-

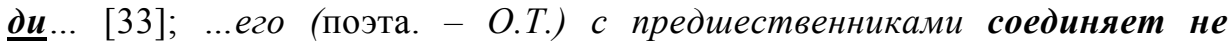
столько традиция, сколько отрицание [34. Т. 1. С. 10]. Перестановка членов, соединенных союзами не только... но и, не столько... но и, недопустима, так как при трансформации полностью меняется актуализация смысла высказывания, ср.: не только идеи великие, но и люди $\rightarrow$ *не только люди, но и великие идеи.

Пара имен в позиции субъекта, соединенных союзами так и либо как $u$, выражают присоединительные или присоединительно-сопоставительные отношения, напр.: Шимпанзе, как и дети, соединяют язык знаков и язык тела [35. С. 281]. При перестановке отношение сопоставления сохраняется, но меняется присоединяемый элемент, ср.: *детu, как $u$ иимпанзе, соединяют.

Бессоюзная пара в позиции субъекта обозначает соединение, при котором перечисляются усиливающие (дополняющие) друг друга признаки: Мама надеялась, что праздничная столица, любимые родичи снова соединят их в родственной теплой кутерьме... [36]. Перестановка таких членов субъектной сферы вполне возможна: $\rightarrow$ родичи, столица соединят. 
Таким образом, конструкции с двумя (и более) именами в позиции подлежащего при глаголах «соединить / соединять» в активной форме имеют ряд грамматических особенностей. Приведенный в статье иллюстративный материал свидетельствует, что два (или более) имени в современном русском предложении могут быть представлены в позиции подлежащего при разных формах глагола «соединения»: несовершенного и совершенного вида; изъявительного наклонения (всех трех времен), повелительного и сослагательного наклонения. Описываемые ряды имен в субъектной сфере соединяются между собой союзной связью и бессоюзной (реже), при этом союзная связь представлена (гораздо чаще) сочинительной разновидностью. На языковом материале, приведенном в статье, показано, что пара имен, репрезентированных в позиции подлежащего, допускает перестановку членов, если последующий член содержательно не обусловлен предыдущим.

\section{Литература}

1. Холодович А.А. Залог. 1: Определение. Исчисление // Категория залога: материалы конф. Л., 1970. С. $2-26$.

2. Лексико-семантические группы русских глаголов: учебн. слов.-справ. / под общ. ред. Т.В. Матвеевой. Свердловск: Изд-во Урал. ун-та, 1988. 153 с.

3. Большой толковый словарь русских глаголов: идеографическое описание: Английские эквиваленты. Синонимы. Антонимы / под общ. ред. Л.Г. Бабенко. М.: АСТ-ПРЕСС: КНИГА, 2007. 576 с. (Фундаментальные словари).

4. Васильев Л.М. Системный семантический словарь русского языка. Предикатная лексика. Т. 1. Уфа: Гилем, 2005. 466 с.

5. Национальный корпус русского языка [Электронный ресурc]. URL: http:// search. ruscorpora.ru/ (дата обращения: 05.12.2015).

6. Сазонова И.К. Русский глагол и его причастные формы: Толково-грамматич. слов. М. : Рус. яз., 1989.590 c.

7. Золотова Г.А., Онипенко Н.К., Сидорова М.Ю. Коммуникативная грамматика русского языка. М.: Институт русского языка им. В.В. Виноградова РАН, 1998. 528 с.

8. Твердохлеб О.Г. Валентностное окружение глагола «соединить»: агенс (сверхъестественное существо) - объект // ФИЛОLOGOS. Вып. 2(25). Елец, 2015. С. 62-66.

9. Твердохлеб О.Г. Валентностное окружение глагола соединить: 1. Агенс // Вестн. Юж.Урал. гос. ун-та. Сер. Лингвистика. 2015. Т. 12, № 4. С. 5-7.

10. Князев Ю.П. Грамматическая семантика: Русский язык в типологической перспективе. М.: Языки славянских культур, 2007. 704 с.

11. Недялков В.П. Типология взаимных конструкций // Теория функциональной грамматики : Персональность. Залоговость / отв. ред. А.В. Бондарко. СПб., 1991. С. 276-312.

12. Никитин Ю.А. Труба Иерихона. М.: Эксмо, 2003. 480 с. [Электронный ресурс]. URL: http://books.rusf.ru/unzip/add-on/xussr_mr/nikit54.htm?14/56 (дата обращения: 27.01.2016).

13. Степанов Ю.С. Константы: Словарь русской культуры. М.: Языки русской культуры, 1997. $824 \mathrm{c}$.

14. Чернышевский Н.Г. Полное собрание сочинений. Т. 8. М.: Худож. лит., 1950. С. 275.

15. Рaйm O.T. Островитяния. T. 1. М. : Терpa, 1996. 480 с. [Электронный ресурс]. URL: www.libros.am/book/read/id/258891/slug/ostrovityaniya-tom-pervyjj (дата обращения: 27.01.2016).

16. Паньков В. Золото // Стихи.ру [Электронный ресурc]. URL: https://www.stihi.ru/2005/ 05/30-1276 (дата обращения: 27.01.2016).

17. Симонов К.М. Так называемая личная жизнь // Собр. соч.: в 10 т. Т. 7. М., 1982. С. 389.

18. Приворот на любовь // Приворот [Электронный pecypc]. URL: http://iwitch.ru/ $\operatorname{tag} / \% \mathrm{D} 0 \% \mathrm{BF} \% \mathrm{D} 1 \% 80 \% \mathrm{D} 0 \% \mathrm{~B} 8 \% \mathrm{D} 0 \% \mathrm{~B} 2 \% \mathrm{D} 0 \% \mathrm{BE} \% \mathrm{D} 1 \% 80 \% \mathrm{D} 0 \% \mathrm{BE} \% \mathrm{D} 1 \% 82-2 /$ (дата обращения: 27.01.2016).

19. Достоевская А.Г. Дневник 1867 года / изд. подгот. С.В. Житомирская. М.: Наука, 1993. 454 с. [Электронный ресурc]. URL: https://books.google.ru/ books?isbn=5457354075 (дата обращения: 27.01.2016). 
20. Записки Юлия Цезаря и его продолжателей о Галльской войне, о гражданской войне, об Александрийской войне, об Африканской войне / под ред. М.М. Покровского. М.: Изд-во АН CCCP, 1948. 570 с. [Электронный ресурс]. URL: https://books.google.ru/books?isbn=5998914961

21. Доброва E.B. Популярная история мифологии. М.: Вече, 2003. 512 с.

22. Брэм А.Э. Путешествие по северо-восточной Африке или по странам, подвластным Египту: Судану, Нубии, Сеннару, Россересу и Кордофану : в 2 ч. СПб., 1869. Ч. 1. 320 с.; Ч. 2. 514 с. [Электронный ресурс]. URL: https://books.google.ru/ books?id= oеoxAQAAIAAJ (дата обращения: 27.01.2016).

23. Хлебников В. Лебедия будущего // Собр. соч.: в 3 т. М., 2001. Т. 3. С. 234.

24. Басилов B.Н. Шаманство у народов Средней Азии и Казахстана. М.: Наука, 1992. 328 с.

25. Водовозов В.И. Новая русская литература (От Жуковского до Гоголя включительно). СПб.: Россійская Имперія, изданіе И.П. Мазурецъ, 1908. 393 с. [Электронный ресурс]. URL: https://books.google.ru/ books?isbn= 5446092058 (дата обращения: 27.01.2016).

26. Скобелев И.Н. Переписка и рассказы русского инвалида // Московский наблюдатель. СПб., 1838. Ч. 18, авг., кн. 2 // Национальный корпус русского языка [Электронный ресурс]. URL: http://search.ruscorpora.ru/ (дата обращения: 05.12.2015).

27. Бальзак О. де. История Цезаря Биротто // Библиотека для чтения: журнал словесности, наук и политики. 1838. Т. 29 [Электронный ресурc]. URL: https://books.google.ru/ books?id=9_ I6AQAAMAАJ (дата обращения: 27.01.2016).

28. Шкловский В.Б. Гамбургский счет: Статьи - воспоминания - эссе (1914-1933). М.: Советский писатель, 1990. 720 с. [Электронный ресурс]. URL: https://books.google.ru/ books? isbn=5457074382 (дата обращения: 27.01.2016).

29. Крылов И.А. Рассуждения о дружестве // Крылов И.А. Избр. соч.: в 2 т. М., 1984. Т. 1. 467 с. [Электронный ресурс]. URL: https://books. google.ru/books?id= Wms2 THxLQFwC (дата обращения: 27.01.2016).

30. Ладинский А.П. В дни Каракаллы. М.: АСТ: Фолио, 1998. 624 с. [Электронный ресурс]. URL: https://books.google.ru/books?isbn=5457071863 (дата обращения: 27.01.2016).

31. Булгарин Ф.В. Иван Иванович Выжигин // Сочинения / сост., авт. Вступ. ст. и примеч. Н.Н. Львова. М., 1990. 704 с. [Электронный ресурс]. URL: https://books.google.ru/ books?isbn= 5457039293 (дата обращения: 27.01.2016).

32. Амфuтеатров A.B. Бабы и дамы. М., 1911. 227 с. [Электронный ресурc]. URL: https:// books.google.ru/ books? isbn=5447857732 (дата обращения: 27.01.2016).

33. Андронников И.Л. А теперь об этом. М.: Сов. писатель, 1985. 544 с. [Электронный реcypc]. URL: https://books.google.ru/books?id=dndgAAAAMAA (дата обращения: 27.01.2016).

34. Шкловский В.Б. Собрание сочинений. Т. 1. М.: Худож. лит., 1973. С. 10.

35. Зорина 3.А., Смирнова А.А. О чем рассказали «говорящие обезьяны». М.: Языки славянских культур, 2006. 423 с.

36. Попов В.Г Сон, похожий на жизнь. М.: ПРОЗАиК, 2010. 512 с. [Электронный ресурс]. URL: https://books.google.ru/books?id=xXs8AQAAIAAJ (дата обращения: 27.01.2016).

\section{GENERAL GRAMMATICAL CHARACTERISTICS OF STRUCTURES WITH A COM- BINED SUBJECT OF VERBS DENOTING CONNECTION}

Vestnik Tomskogo gosudarstvennogo universiteta. Filologiya - Tomsk State University Journal of Philology. 2016.3 (41). 57-65. DOI: 10.17223/19986645/41/5

Tverdokhleb Olga G., Orenburg State Pedagogical University (Orenburg, Russian Federation). E-mail: ogtwrd@gmail.com

Keywords: subject, lexical-semantic group of verbs, combined subject, syndesis.

The article summarizes some results of the study of grammatical features of constructions with two (or more) names in the subject and the verb soedinyat' [to connect] in the active voice.

The work focuses on the morphological characteristics of the verb denoting connection in these constructions. The material for the study was selected by continuous and partial sampling; it includes more than three thousand examples. It shows that two (or more) names are subjects with the verb in different forms, in particular: in the imperfective and perfective forms of "to connect"; in the three tenses of the verb in the indicative mood; in the imperative and subjunctive mood forms of the verb.

Special attention is paid to the means of connection between two (or more) names in the subject with the verb "to connect", as well as the possibility / impossibility of shifting these elements. The described constructions generally have two, less frequently three, names in the subject. 
Names in the subject position are connected syndetically and asyndetically (less frequently); the syndetic connections are generally coordinating. Two (or more) names are usually connected by a single conjunction $i$ [and] that signifies the end of the enumerated elements.

Pairs of names connected by "and", $i l i, l i$ [or] or asyndetically allows shifting their members. If the subject is expressed by four homogeneous parts, divided in pairs and connected by "and", shifting is allowed within each pair of names.

Shifting members is impossible in some cases: 1) if the following member is semantically dependent on the previous one; 2 ) in pairs with conjunctions ne... a (a ne); ne... no (no ne) [not ... but], because the transformation changes the meaning of the statement; 3 ) if there is a relative limit, e.g., in relation to the second member expressed by introductory words; 4) if members of the subject connected by the repetition of "or" are represented by the pair "noun + pronoun dependent on the noun"; 6) if members of the subject are connected by the conjunctions ne tol'ko... no $i$; ne stol'ko... no $i$ [not only ... but also], because the transformation changes the actualization of the meaning of the statement; 7) if members of the subject are connected by conjunctions tak $i, k a k i$ [as well as], because the comparison is preserved yet the joining element changes.

The proposed methodology of describing structures with the combined subject may be interesting for the study of reciprocal constructions and symmetric relations.

\section{References}

1. Kholodovich, A.A. (1970) [Voice. 1: Definition. Identification]. Kategoriya zaloga [The Category of Voice]. Proceedings of the conference. Leningrad: Nauka. pp. 2-26. (In Russian).

2. Matveeva, T.V. (ed.) (1988) Leksiko-semanticheskie gruppy russkikh glagolov: Uchebn. slov.sprav. [The lexical-semantic groups of Russian verbs: Study dictionary]. Sverdlovsk: Ural State University.

3. Babenko, L.G. (ed.) (2007) Bol'shoy tolkovyy slovar' russkikh glagolov: ideograficheskoe opisanie. Angl. ekvivalenty. Sinonimy. Antonimy [The Great Dictionary of Russian verbs: ideographic description. English equivalents. Synonyms. Antonyms]. Moscow: AST-PRESS KNIGA.

4. Vasil'ev, L.M. (2005) Sistemnyy semanticheskiy slovar' russkogo yazyka. Predikatnaya leksika [The system semantic dictionary of the Russian language. Predicate vocabulary]. Vol. 1. Ufa: Gilem.

5. The Russian National Corpus. [Online]. Available from: http://search.ruscorpora.ru/. (Accessed: 05 December 2015). (In Russian).

6. Sazonova, I.K. (1989) Russkiy glagol i ego prichastnye formy: Tolkovo-grammatich. sl. [Russian verb and its participial forms: Explanatory-grammatical dictionary]. Moscow: Russkiy yazyk.

7. Zolotova, G.A., Onipenko, N.K. \& Sidorova, M.Yu. (1998) Kommunikativnaya grammatika russkogo yazyka [Communicative Grammar of the Russian language]. Moscow: Russian Language Institute RAS.

8. Tverdokhleb, O.G. (2015) Valentnostnoe okruzhenie glagola "soedinit": agens (sverkh" estestvennoe sushchestvo) - ob"ekt [Valency environment of the verb "to connect": agens (supernatural being) - object]. In: FILOLOGOS. Is. 2 (25). Elets: Elets State University. pp. 62-66.

9. Tverdokhleb, O.G. (2015) Valentnostnoe okruzhenie glagola soedinit': 1. Agens [Valency environment of the verb "to connect":1. Agens]. Vestnik Yuzhno-Ural'skogo gosudarstvennogo universiteta. Seriya "Lingvistika". 12:4. pp. 5-7.

10. Knyazev, Yu.P. (2007) Grammaticheskaya semantika: Russkiy yazyk v tipologicheskoy perspektive [Grammatical semantics: The Russian language in a typological perspective]. Moscow: Yazyki slavyanskikh kul'tur.

11. Nedyalkov, V.P. (1991) Tipologiya vzaimnykh konstruktsiy [Typology of reciprocal structures]. In: Bondarko, A.V. (ed.) Teoriya funktsional'noy grammatiki: Personal'nost'. Zalogovost' [The theory of functional grammar: Person. Aspect]. St. Petersburg: Nauka.

12. Nikitin, Yu.A. (2003) Truba Ierikhona [Trumpet of Jericho]. Moscow: Eksmo.[Online]. Available from: http://books.rusf.ru/unzip/add-on/xussr_mr/nikit54.htm?14/56. (Accessed: 27 January 2016).

13. Stepanov, Yu.S. (1997) Konstanty: Slovar' russkoy kul'tury [Constants: The Dictionary of Russian Culture]. Moscow: Yazyki russkoy kul'tury.

14. Chernyshevskiy, N.G. (1950) Polnoe sobranie sochineniy [Complete works]. Vol. 8. Moscow: Khudozhestvennaya literatura. 
15. Wright, A.T. (1996) Ostrovityaniya [Islandia]. Vol. 1. Moscow: Terra. [Online]. Available from: www.libros.am/book/read/id/258891/slug/ostrovityaniya-tom-pervyjj. (Accessed: 27 January 2016).

16. Pan'kov, V. (2005) Zoloto [Gold]. [Online]. Available from: https://www.stihi.ru/2005/05/301276. (Accessed: 27 January 2016).

17. Simonov, K.M. (1982) Tak nazyvaemaya lichnaya zhizn' [The so-called private life]. In: Simonov, K.M. Sobranie sochineniy v $10 \mathrm{tt}$. [Collected works in 10 vols]. Vol. 7. Moscow: Khudozhestvennaya literatura.

18. Privorot. (n.d.) Privorot na lyubov' [A spell for love]. [Online]. Available from: http://iwitch.ru/tag/\%D0\%BF\%D1\%80\%D0\%B8\%D0\%B2\%D0\%BE\%D1\%80\%D0\%BE\%D1\%82-2/. (Accessed: 27 January 2016).

19. Dostoevskaya, A.G. (1993) Dnevnik 1867 goda [A diary for 1867]. Moscow: Nauka. [Online]. Available from: https://books.google.ru/books?isbn=5457354075. (Accessed: 27 January 2016).

20. Pokrovskiy, M.M. (ed.) (1948) Zapiski Yuliya Tsezarya i ego prodolzhateley o Gall'skoy voyne, o grazhdanskoy voyne, ob Aleksandriyskoy voyne, ob Afrikanskoy voyne [Notes of Julius Caesar and his successors on the Gallic War, the Civil War, War of Alexandria, on the African War]. Moscow: USSR AS. [Online]. Available from: https://books.google.ru/books?isbn=5998914961.

21. Dobrova, E.V. (2003) Populyarnaya istoriya mifologii [The popular history of mythology]. Moscow: Veche.

22. Brem, A.E. (1869) Puteshestvie po severo-vostochnoy Afrike ili po stranam, podvlastnym Egiptu: Sudanu, Nubii, Sennaru, Rosseresu i Kordofanu: v 2 ch. [Travel Northeast Africa or countries subservient to Egypt: Sudan, Nubia, Sennar, Rosseresu and Kordofan: in 2 pts]. St. Petersburg: Tip. Germana Myullera. [Online]. Available from: https://books.google.ru/books?id=oeoxAQAAIAAJ. (Accessed: 27 January 2016).

23. Khlebnikov, V. (2001) Lebediya budushchego [Lebedia of the future]. In: Khlebnikov, V. Sobranie sochineniy. V $3 \mathrm{tt}$. [Collected Works. In 3 vols]. Vol. 3. Moscow: Akademicheskiy proekt.

24. Basilov, V.N. (1992) Shamanstvo u narodov Sredney Azii i Kazakhstana [Shamanism among the peoples of Central Asia and Kazakhstan]. Moscow: Nauka.

25. Vodovozov, V.I. (1908) Novaya russkaya literatura (Ot Zhukovskogo do Gogolya vklyuchitel'no) [The new Russian literature (from Zhukovsky to Gogol inclusive)]. St. Petersburg: Rossiyskaya Imperiya, izdanie I.P. Mazurets. [Online]. Available from: https:// books.google.ru/ books? isbn=5446092058. (Accessed: 27 January 2016).

26. Skobelev, I.N. (1838) Perepiska i rasskazy russkogo invalida [Correspondence and stories of a Russian invalid]. In: Moskovskiy nablyudatel' [Moscow observer]. Pt. XVIII. August. Book 2 St. Petersburg: Tipografiya N. Grecha. [Online]. Available from: http://search.ruscorpora.ru/. (Accessed: 05 December 2015).

27. Balzac, O. de. (1838) Istoriya Tsezarya Birotto [The story of Cesar Birotteau]. Biblioteka dlya chteniya: zhurnal slovesnosti, nauk i politiki. 29. [Online]. Available from: https://books. google.ru/ books?id=9_I6AQAAMAAJ. (Accessed: 27 January 2016).

28. Shk̄lovskiy, V.B. (1990) Gamburgskiy schet: Stat'i - vospominaniya - esse (1914-1933) [Hamburg reckoning: Articles - memoirs - essays (1914-1933)]. Moscow: Sovetskiy pisatel'. [Online]. Available from: https://books.google.ru/books?isbn=5457074382. (Accessed: 27 January 2016).

29. Krylov, I.A. (1984) Rassuzhdeniya o druzhestve [Arguments about friendship]. In: Krylov, I.A. Izbrannye sochineniya $v$ 2-kh $t$. [Selected Works in 2 vols]. Vol. 1. Moscow: Khudozhestvennaya literatura. [Online]. Available from: https://books.google.ru/books?id=Wms2THxLQFwC. (Accessed: 27 January 2016).

30. Ladinskiy, A.P. (1998) $V$ dni Karakally [In the days of Caracalla]. Moscow: AST, Folio. [Online]. Available from: https://books.google.ru/books?isbn=5457071863. (Accessed: 27 January 2016).

31. Bulgarin, F.V. (1990) Ivan Ivanovich Vyzhigin [Ivan Vyzhigin]. In: Bulgarin, F.V. Sochineniya [Works]. Moscow: Sovremennik. [Online]. Available from: https:// books.google.ru/ books?isbn= 5457039293. (Accessed: 27 January 2016).

32. Amfiteatrov, A.V. (1911) Baby $i$ damy [Women and ladies]. Moscow: Tipografiya A.P. Poplavskogo. [Online]. Available from: https://books.google.ru/books?isbn=5447857732. (Accessed: 27 January 2016). 
33. Andronnikov, I.L. (1985) A teper' ob etom [And now this]. Moscow: Sovetskiy pisatel'. [Online]. Available from: https://books.google.ru/books?id=dndgAAAAMAA. (Accessed: 27 January 2016).

34. Shklovskiy, V.B. (1973) Sobranie sochineniy [Works]. Vol. 1. Moscow: Khudozhestvennaya literatura.

35. Zorina, Z.A. \& Smirnova, A.A. (2006) O chem rasskazali “govoryashchie obez'yany” [What "talking monkeys" told]. Moscow: Yazyki slavyanskikh kul'tur.

36. Popov, V.G. (2010) Son, pokhozhiy na zhizn' [Life-like dream]. Moscow: PROZAiK. [Online]. Available from: https://books.google.ru/books?id=xXs8AQAAIAAJ. (Accessed: 27 January 2016). 